\title{
FACILE ONE-POT SYNTHESIS OF SPIROACENAPHTHYLENE DERIVATIVES USING SBA-Pr-NH
}

\author{
G. MOHAMMADI ZIARANI ${ }^{*}$, P. HAJIABBASI', A. BADIEI ${ }^{2}$, M. AMANLOU ${ }^{3}$ \\ 'Department of Chemistry, Alzahra University, Vanak Square, Tehran, Iran. \\ ${ }^{2}$ School of Chemistry, College of Science, University of Tehran, Tehran, Iran; \\ ${ }^{3}$ Drug Design and Development Research Center and Department of Medicinal Chemistry, Faculty of Pharmacy, \\ Tehran University of Medical Sciences, Tehran, Iran.
}

ABSTRACT

A simple procedure afforded novel spiroacenaphthylene derivatives in high yields at room temperature from acenaphthenequinone, malononitrile, and phenol derivatives using amino-functionalized silica $\left(\mathrm{SBA}-\mathrm{Pr}-\mathrm{NH}_{2}\right.$ ) as a heterogeneous efficient solid base catalyst. Using SBA-Pr- $\mathrm{NH}_{2}$ in the current procedure presents several advantages, such as a simpler procedure, shorter reaction times, facile synthesis, and simpler work-up. Also, recycling of the catalyst was completed with no significant decrease in the activity of catalyst.

Keywords: amino-functionalized silica $\left(\mathrm{SBA}-\mathrm{Pr}-\mathrm{NH}_{2}\right)$, spiroacenaphthylene, heterogeneous catalyst, green synthesis.

\section{INTRODUCTION}

Spiro compounds are known for their biological properties and presence in an important class of naturally occurring substance s., $^{1}$ such as alkaloids, lactones or terpenoids. ${ }^{3}$ Nowadays, medicinal structures commonly consist of rigid hetero ring systems, among them spiro-chromene, -pyran, -pyrimidine, and -pyrazole cycles are required for target recognition. ${ }^{4}$ For example, spiropyrans have potential activity as hypertensive and analgesic agents ${ }^{5}$ and they were applied in industrial fields. ${ }^{6}$ Functionalized and spiro-chromenes have also played an important role in the synthetic approaches of pharmaceuticals. ${ }^{7}$

In recent decades, organic chemists pay much more attention to search more efficient procedures, which allow for the rapid generation of molecular complexity and diversity from simple and readily accessible starting materials. Among them, the strategically use of multicomponent reactions ${ }^{9}$ has constituted an efficient method for the construction of complex molecules. Thus, in continuation of our studies in the field of nano catalyst applications in multicomponent reactions,$^{10}$ we explored the high catalytical activity of amino functionalized silica (SBA-Pr- $\mathrm{NH}_{2}$ ) toward the synthesis of novel spirochromenes derivatives, beside our pervious exploration of its efficiency (Scheme 1). However, the three-component condensation of acenaphthequinone 1 , malononitrile 2 and various reagents including $\alpha$-methylen carbonyl compounds/enols in the presence of triethylamine $\left(\mathrm{Et}_{3} \mathrm{~N}\right)$ as catalyst and electrolysis procedure was performed. ${ }^{11,12,13}$

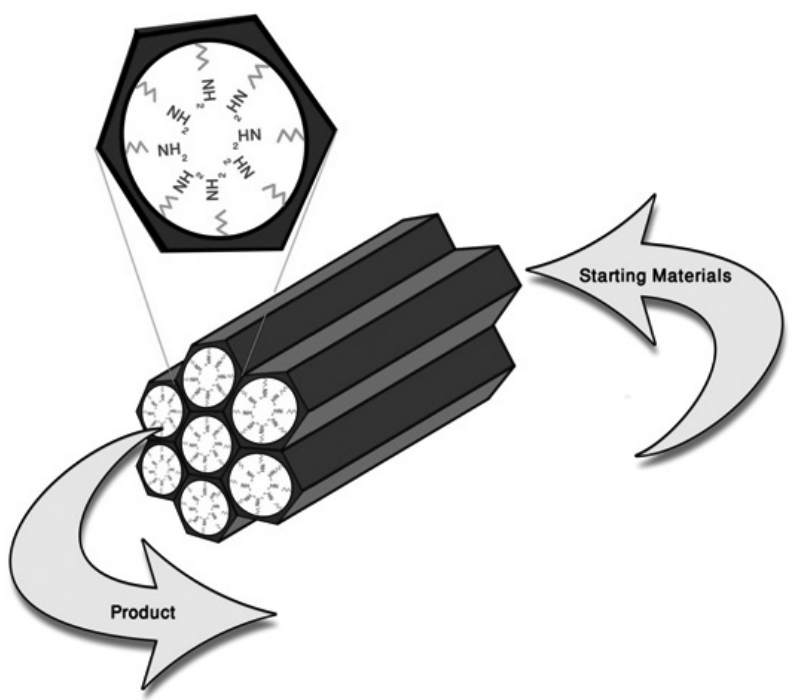

Scheme 1. Amino-functionalized nanoporous silica $\left(\mathrm{SBA}-\mathrm{Pr}-\mathrm{NH}_{2}\right)$ as a nano catalyst.

\section{EXPERIMENTAL}

\section{1 general information}

All chemicals were obtained commercially and used without further purification. IR spectra were recorded from $\mathrm{KBr}$ disk using a FT-IR Bruker Tensor 27 instrument. Melting points were measured by using the capillary tube method with an Electrothermal 9200 apparatus. The ${ }^{1} \mathrm{H}$ NMR ( 500 \& $300 \mathrm{MHz}$ ) was run on a Bruker DPX using TMS as an internal standard. Gas chromatographymass spectrometry (GC-MS) analysis was performed on an Agilent 6890-5973 $\mathrm{GC} / \mathrm{MS}$ detector. Nitrogen adsorption-desorption isotherms were measured at $196{ }^{\circ} \mathrm{C}$ using a BELSORP-mini II. The specific surface area $\left(A_{B E T}\right)$ was evaluated using the Brunauer-Emmett-Teller (BET) equation, and the pore size distribution $\left(D_{B H H}\right)$ was obtained from the desorption branches by means of the Barret-Joyner-Halenda $(\mathrm{BJH})$ model, with the pore volume being taken at $p / p_{0}$ $=0.995$. Transmission electron microscopy (TEM) analysis was performed on a Tecnai G2 F30 at $300 \mathrm{kV}$.

\subsection{SBA-15 nanoporous silica synthesis and functionalization}

Pluronic P123 nonionic surfactant as a structure directing agent and TEOS were used under acidic conditions to synthesis SBA-15 similar to that described previously in the literature. ${ }^{14,15}$ The post-synthesis grafting method was utilized for surface modifications over the nanoporous silica with aminopropyl moieties. ${ }^{16}$ In a typical procedure, calcined SBA-15 (5 g) was activated at 200 ${ }^{\circ} \mathrm{C}$ under vacuum for $5 \mathrm{~h}$ to remove any surface humidity and then refluxed in dry toluene $(150 \mathrm{ml})$. Subsequently, APTES $(30.2 \mathrm{mmol})$ was gradually added to the mixture and the reaction was refluxed at $110^{\circ} \mathrm{C}$ for a further $24 \mathrm{~h}$. The mixture was then filtered and washed with toluene and any residual organosilane was taken out by Soxhlet extraction in ethanol over a $24 \mathrm{~h}$ period. The resulting material was indicated as $\mathrm{NH}_{2}-\mathrm{SBA}-15$.

2.3 General procedure for the preparation of spiroacenaphthylene derivatives (4a-4i)

The SBA-Pr- $\mathrm{NH}_{2}(0.02 \mathrm{~g})$ was activated in vacuum at $100{ }^{\circ} \mathrm{C}$ and then after cooling to room temperature, acenaphthenequinone $1(1 \mathrm{mmol})$, malononitrile $2(1 \mathrm{mmol})$, and phenol derivatives $3(1 \mathrm{mmol})$ were added to it. The mixture was stirred in ethanol at room temperature for an appropriate time to produce spiroacenaphthylene derivatives $4 \mathrm{a}-4 \mathrm{i}$. The completion of reaction was indicated by TLC, the resulting solid product was dissolved in hot acetonitrile and ethyl acetate, filtered for removing the unsolvable catalyst and then the filtrate was cooled to give the pure orange product. The spectroscopic and analytical data for compounds are presented in the following part. Finally, the recovered catalyst could then be washed sequentially with diluted aqueous $\mathrm{Et}_{3} \mathrm{~N}$ solution, water, and acetone. Following a period of drying, the catalyst could be reused without any noticeable loss in reactivity.

2'-Amino-6'-methoxy-2-ox0-2H-spiro[acenaphthylene-1, $\mathbf{4}^{\prime}$ chromene]-3'-carbonitrile (4b)

mp: $243-245^{\circ} \mathrm{C}$. IR (KBr, $\left.v_{\text {max }}\left(\mathrm{cm}^{-1}\right)\right): 3480,3086,2969,2203,1718$, $1671,1597,1572,1356,804,781 .{ }^{\max } \mathrm{H}$ NMR $\left(500 \mathrm{MHz}, \mathrm{CDCl}_{3}\right): \delta 3.82(\mathrm{~s}, 3 \mathrm{H}$, $\left.\mathrm{OCH}_{3}\right), 7.90(\mathrm{~m}, 4 \mathrm{H}, \mathrm{Ar}-\mathrm{H}), 8.20(\mathrm{~d}, \mathrm{~J}=7 \mathrm{~Hz}, 2 \mathrm{H}, \mathrm{Ar}-\mathrm{H}), 8.27(\mathrm{dd}, \mathrm{J}=8.4$, $3 \mathrm{H}, \mathrm{Ar}-\mathrm{H}), 8.62\left(\mathrm{~s}, 2 \mathrm{H}, \mathrm{NH}_{2}\right)$. EI-MS: $354\left(\mathrm{M}^{+}\right), 230(100), 202(50), 175(30)$, 149 (10). 
2'-Amino-7'-methyl-2-oxo-2H-spiro[acenaphthylene-1,4'-chromene]3 '-carbonitrile (4c)

$\mathrm{mp}: 248-250{ }^{\circ} \mathrm{C}$. IR $\left(\mathrm{KBr}, v_{\max }\left(\mathrm{cm}^{-1}\right)\right): 3424,3083,2923,2223,1719$, $1624,1592,1280,1026,780 .{ }^{1} \mathrm{H}$ NMR $\left(500 \mathrm{MHz}, \mathrm{CDCl}_{3}\right): \delta 1.58\left(\mathrm{~s}, 3 \mathrm{H}, \mathrm{CH}_{3}\right)$, 7.90 (q, 4H, Ar-H), 8.20 (d, J = 6.95 Hz, 2H, Ar-H), 8.28 (d, J = 8.1, 3H, Ar-H), $8.60\left(\mathrm{~s}, 2 \mathrm{H}, \mathrm{NH}_{2}\right)$. EI-MS: $338\left(\mathrm{M}^{+}\right), 175(60), 149(10)$.

2'-Amino-6'-bromo-2-0x0-2H-spiro[acenaphthylene-1,4'-chromene]$3^{\prime}$-carbonitrile (4d)

mp: $276-278{ }^{\circ} \mathrm{C}$. IR (KBr, $\left.v_{\max }\left(\mathrm{cm}^{-1}\right)\right): 3424,3085,2223,1719,1571$, $1279,1025,836,779 .{ }^{1} \mathrm{H}$ NMR $\left(300 \mathrm{MHz}, \mathrm{CDCl}_{3}\right): \delta$ 7.90-7.98 (m, 4H, Ar-H), 8.19-8.28 (d, J = 7.6, 4H, Ar-H), 8.37-8.43 (m, 1H, Ar-H), $8.61\left(\mathrm{~S}, 2 \mathrm{H}, \mathrm{NH}_{2}\right)$. EI-MS: $402\left(\mathrm{M}^{+}\right), 167(45), 139(20), 101(20)$.

2'-Amino-6'-nitro-2-oxo-2H-spiro[acenaphthylene-1,4'-chromene]-3'carbonitrile (4e)

mp: $243-245{ }^{\circ} \mathrm{C}$. IR $\left(\mathrm{KBr}, v \quad\left(\mathrm{~cm}^{-1}\right)\right): 3423,3087,2222,1719,1570$, 1279, 1025, 836, 780. ${ }^{1} \mathrm{H}$ NMR (500 MHz, $\mathrm{CDCl}_{3}$ ): $\delta 7.90$ (m, 4H, Ar-H), 8.20 $(\mathrm{d}, \mathrm{J}=7.05 \mathrm{~Hz}, 2 \mathrm{H}, \mathrm{Ar}-\mathrm{H}), 8.27$ (dd, J = 8.3, 3H, Ar-H), $8.62\left(\mathrm{~s}, 2 \mathrm{H}, \mathrm{NH}_{2}\right)$. EI-MS: $369\left(\mathrm{M}^{+}\right), 115(8), 101(25)$.

2'-Amino-3'-cyano-2-oxo-2H-spiro[acenaphthylene-1,4'-chromene]6'-carboxylicacid (4f)

mp: $252-253^{\circ} \mathrm{C}$. IR $\left(\mathrm{KBr}, v_{\max }\left(\mathrm{cm}^{-1}\right)\right): 3449\left(\mathrm{OH}, \mathrm{NH}_{2}\right), 3059,2226,1714$, $1641,1574,1408,1267,776 .{ }^{1} \mathrm{H}$ NMR $\left(300 \mathrm{MHz}, \mathrm{CDCl}_{3}\right): \delta 7.87-7.93(\mathrm{~m}$, 4H, Ar-H, OH), 8.18-8.20 (d, J = 7.0, 2H, Ar-H), 8.26-8.29 (d, J = 8.4 Hz, 4H, Ar-H), 8.59 (s, 2H, NH $)$. EI-MS: $368\left(\mathrm{M}^{+}\right), 238$ (8), 230 (100), 175 (37), 126 (12), 74 (39), 63 (40).

2'-Amino-6'-hydroxy-2-oxo-2H-spiro[acenaphthylene-1, $4^{\prime}$ chromene]-3'-carbonitrile (4g)

mp: 261-263 ${ }^{\circ} \mathrm{C}$. IR $\left(\mathrm{KBr}, v\left(\mathrm{~cm}^{-1}\right)\right): 3449\left(\mathrm{OH}, \mathrm{NH}_{2}\right), 3069,2226,1629$, $1588,1451,1257,1216,1148,778 .{ }^{1} \mathrm{H}$ NMR $\left(300 \mathrm{MHz}, \mathrm{CDCl}_{3}\right): \delta 7.85-8.46$ $(10 \mathrm{H}, \mathrm{Ar}-\mathrm{H}, \mathrm{OH}), 8.62\left(\mathrm{~s}, 2 \mathrm{H}, \mathrm{NH}_{2}\right)$. EI-MS: $340\left(\mathrm{M}^{+}\right), 126,101,74$.

2' - A min o-6' - hydroxy-2,7', 12'-trioxo-7', 12' - dihydro- $2 \mathrm{H}$ spiro[acenaphthylene-1,4'-naphtho[2,3- $h$ ] chromene]-3'-carbonitrile (4h)

$\mathrm{mp}: 199-201^{\circ} \mathrm{C}$. IR $\left(\mathrm{KBr}, v \quad\left(\mathrm{~cm}^{-1}\right)\right): 3449\left(\mathrm{OH}, \mathrm{NH}_{2}\right), 1630,1588,1451$, $1357,1257,1216,1148,778 .{ }^{1} \mathrm{H}$ NMR $\left(300 \mathrm{MHz}, \mathrm{CDCl}_{3}\right): \delta$ 7.28-7.31 (m, $1 \mathrm{H}$, Ar-H), 7.83-7.86 (m, 7H, Ar-H, NH $)$, 8.33-8.36 (m, 6H, Ar-H, OH). EI-MS: $470\left(\mathrm{M}^{+}\right), 391,240,212,183,128,102,77$.

\section{RESULTS AND DISCUSSION}

Herein we report a green approach for the synthesis of some novel spiroacenaphthylene derivatives catalyzed by SBA-Pr- $\mathrm{NH}_{2}$ in EtOH at room temperature using acenaphthenequinone 1 , malononitrile 2 , and phenol derivatives 3 (Scheme 2). Initially, in order to optimize the reaction conditions, we examined different solvents such as $\mathrm{CH}_{3} \mathrm{CN}, \mathrm{DMF}$ and $\mathrm{MeOH}$ in the presence of catalyst at rt. as shown results in Table 1. Comparable condition is shown in Table 1 that was reported without the catalyst at reflux. ${ }^{11}$ For example, $2^{\prime}$-amino-2oxo- $2 H$-spiro[acenaphthylene-1,4'-benzo[ $h]$ chromene]-3'-carbonitrile 4 a was obtained by simple recrystallization from acetonitrile and ethyl acetate in $73 \%$ yield.

So, this reaction was developed with different phenols in EtOH and the results were demonstrated in the Table 2 . The reaction time was within 5-30 min and high yields of desired product obtained. After completion of the reaction (monitored by TLC), the crude product was dissolved in hot acetonitrile and ethyl acetate (with the ratio of 70:30 respectively), the heterogeneous solid catalyst was removed simply by filtration, and after cooling of the filtrate, the pure orange crystals of products were obtained. The catalyst can be reactivated, and then reused without considerable loss of reactivity. The new compounds were characterized by IR, mass, and NMR spectroscopy.<smiles>O=C1C(=O)c2cccc3cccc1c23</smiles><smiles>[3H]C[14CH2][14CH3]</smiles>
2<smiles>Oc1ccccc1</smiles>
$\frac{\mathrm{EtOH}}{\text { rt., SBA-Pr-NH}}$ 3

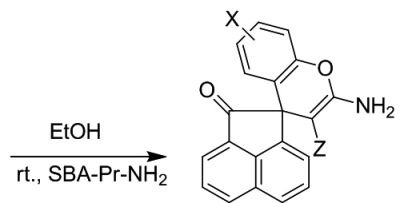

$4 a-4 i$
Scheme 2. Syntheses of spiroacenaphthylene derivatives (4a-4i).
Table 1. The optimization of the reaction condition in the synthesis of spiroacenaphthylene derivatives.

\begin{tabular}{|c|c|c|c|c|c|}
\hline Entry & Conditions & Catalyst & Temperature & $\begin{array}{c}\text { Time } \\
(\mathbf{m i n})\end{array}$ & yield \\
\hline $\mathbf{1}$ & $\mathrm{EtOH}$ & $\mathrm{SBA}^{-P r}-\mathrm{NH}_{2}$ & rt. & 10 & $73 \%$ \\
\hline $\mathbf{2}$ & $\mathrm{CH}_{3} \mathrm{CN}$ & $\mathrm{SBA} \mathrm{Pr}-\mathrm{NH}_{2}$ & rt. & $2 \mathrm{~h}$ & trace \\
\hline $\mathbf{3}$ & $\mathrm{DMF}$ & $\mathrm{SBA}_{2} \mathrm{Pr}-\mathrm{NH}_{2}$ & rt. & 10 & $69 \%$ \\
\hline $\mathbf{4}$ & $\mathrm{MeOH}$ & $\mathrm{SBA}-\mathrm{Pr}_{2} \mathrm{NH}_{2}$ & rt. & 10 & $68 \%$ \\
\hline $\mathbf{5}$ & $\mathrm{EtOH}$ & - & reflux & $4 \mathrm{~h}$ & $70 \%{ }^{11}$ \\
\hline
\end{tabular}

Finally, the recovered catalyst could then be washed sequentially with diluted aqueous Et $\mathrm{N}$ solution, water, and acetone. Following a period of drying, the catalyst could be reused without any noticeable loss in reactivity. The process of recycling was completed four times with no significant decrease in the activity of the catalyst (Fig. 1). The yields for the four runs were establish to be $91 \%, 89 \%, 87 \%$, and $86 \%$, respectively. Also, increasing the amount of catalyst in the optimization procedure didn't show significant increase in the production of $4 \mathrm{a}$ (Table 3$)$.

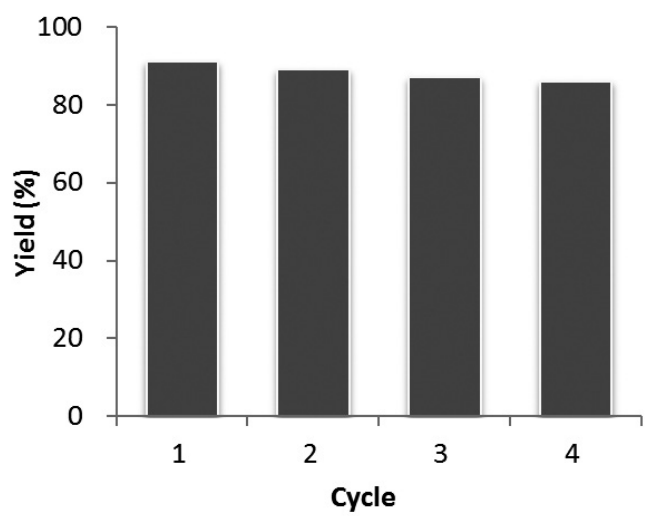

Fig. 1. Reusability of SBA-Pr- $\mathrm{NH}_{2}$ in the synthesis of compound $4 \mathrm{~d}$.

Table 3. The optimization of the amount of catalyst for synthesis of 4a.

\begin{tabular}{|c|c|c|c|}
\hline Entry & Time (min) & SBA-Pr-NH $_{\mathbf{2}}(\mathbf{g r})$ & Yield (\%) \\
\hline $\mathbf{1}$ & 10 & 0.01 & 65 \\
\hline $\mathbf{2}$ & 10 & 0.02 & 73 \\
\hline $\mathbf{3}$ & 10 & 0.03 & 72 \\
\hline $\mathbf{4}$ & 10 & 0.04 & 69 \\
\hline
\end{tabular}

A plausible reaction mechanism and crucial role of SBA-Pr-NH in accelerating the reaction is demonstrated in Scheme 3. First the deprotonation of malononitrile by SBA-Pr- $\mathrm{NH}_{2}$ followed by Knoevenagel condensation of malononitrile 5 with acenaphthenequinone 1 was occurred. Subsequently Michael-type addition of phenols 3 to 6 gives the intermediate 8 which affords the desired products $4 \mathrm{a}-4 \mathrm{i}$ by cyclization of hydroxyl group to the cyano moiety.

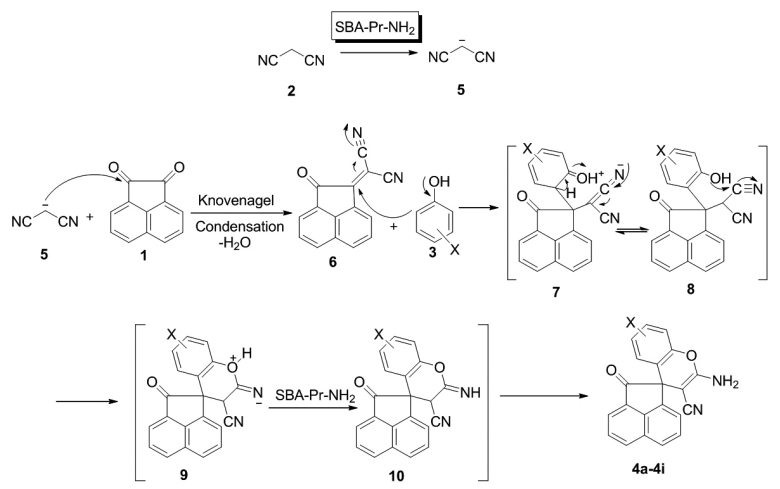

Scheme 3. Proposed mechanism for synthesis of spiroacenaphthylene derivatives $(4 \mathrm{a}-4 \mathrm{i})$ in the presence of SBA-Pr- $\mathrm{NH}_{2}$. 
J. Chil. Chem. Soc., 60, No 2 (2015)

Several different conditions have been reported in the literature for the synthesis of spiroacenaphthylene derivatives, as shown in Table 4. In contrast to the existing methods, the current procedure presents several advantages, such as a simpler procedure, shorter reaction times, facile synthesis, and simpler work-up.

Table 2. Syntheses of novel spiroacenaphthylene derivatives catalyzed by SBA-Pr- $\mathrm{NH}_{2}$ in $\mathrm{EtOH}$.

\begin{tabular}{|c|c|c|c|c|c|c|c|}
\hline Entry & $-Z$ & Reagent 3 & Product & Time (min) & Yield & $\mathrm{Mp}\left({ }^{\circ} \mathrm{C}\right)$ & Mp [Lit] \\
\hline 1 & $-\mathrm{CN}$ & & & 10 & $73 \%$ & $>300$ & $300^{11}$ \\
\hline 2 & $-\mathrm{CN}$ & & & 10 & $76 \%$ & $243-245$ & new \\
\hline 3 & $-\mathrm{CN}$ & & & 10 & $85 \%$ & $248-250$ & new \\
\hline 4 & $-\mathrm{CN}$ & & & 5 & $91 \%$ & $276-278$ & new \\
\hline 5 & $-\mathrm{CN}$ & & & 10 & $82 \%$ & $243-245$ & new \\
\hline 6 & $-\mathrm{CN}$ & & & 5 & $72 \%$ & $252-253$ & new \\
\hline 7 & $-\mathrm{CN}$ & & & 30 & $68 \%$ & $261-263$ & new \\
\hline 8 & $-\mathrm{CN}$ & & & 40 & $52 \%$ & 199-201 & new \\
\hline 9 & $-\mathrm{CN}$ & & & 10 & $71 \%$ & $>300$ & $>300^{11}$ \\
\hline
\end{tabular}


Table 4. Comparison of different conditions in the synthesis of spiroacenaphthylene derivatives (4a-4i)

\begin{tabular}{|c|c|c|c|c|c|c|c|}
\hline Entry & Catalyst & Solvent & Condition & Time (min) & Yield & Year & Ref \\
\hline 1 & $\mathrm{Et}_{3} \mathrm{~N}$ & $\mathrm{EtOH}$ & Reflux & $4-8 \mathrm{~h}$ & $40-85$ & 2010 & 11 \\
\hline 2 & $\mathrm{NaBr}$ & $\mathrm{EtOH}$ & Electrolysis & 15 & $90-95$ & 2012 & 12 \\
\hline 3 & $\mathrm{NH}_{4} \mathrm{Cl}$ & $\mathrm{H}_{2} \mathrm{O}$ & $80{ }^{\circ} \mathrm{C}$ & $10-15$ & $75-90$ & 2009 & 13 \\
\hline 4 & $\mathrm{SBA}^{\mathrm{Pr}-\mathrm{NH}}{ }_{2}$ & $\mathrm{EtOH}$ & r.t. & $5-10$ & $52-91$ & This work \\
\hline
\end{tabular}

\subsection{Catalyst}

Today much attention was afforded to the heterogeneous catalysts due to economic and environmental considerations. ${ }^{17}$ These base catalysts are generally more reactive, eco-friendly, and convenient to handle, with shorter reaction times, simpler work up, high yield of products and better recoverability than most of other catalysts. ${ }^{18}$ Application of these catalysts is a grateful approach in green organic synthesis. Herein, we wish to reveal our results in producing product $4 \mathrm{a}-4 \mathrm{i}$ using SBA-Pr- $\mathrm{NH}_{2}$ as an efficient heterogeneous catalyst to reduce significant amount of the reaction time and temperature condition.

$\mathrm{N}_{2}$ adsorption-desorption isotherms, textural properties of $\mathrm{NH}_{2}-\mathrm{SBA}-15$, XRD pattern, FT-IR spectra, and TEM image of SBA-Pr-NH $\mathrm{N}_{2}$ were discussed in our previous report ${ }^{10 \mathrm{~b}}$ confirming that the surface modification occurred on the inner surface of the silica wall. ${ }^{14}$ For example the "Type IV" $\mathrm{N}_{2}$ adsorptiondesorption isotherms with "H1-type" hysteresis of both materials $\mathrm{NH}_{2}$-SBA-15 and SBA-15 are shown in the Fig. 2. Also, the ordered mesoscopic structured silica is established in the XRD pattern of SBA-15 which exhibits a two-dimensional hexagonal symmetrical array of nano-channels (Fig. 3.).

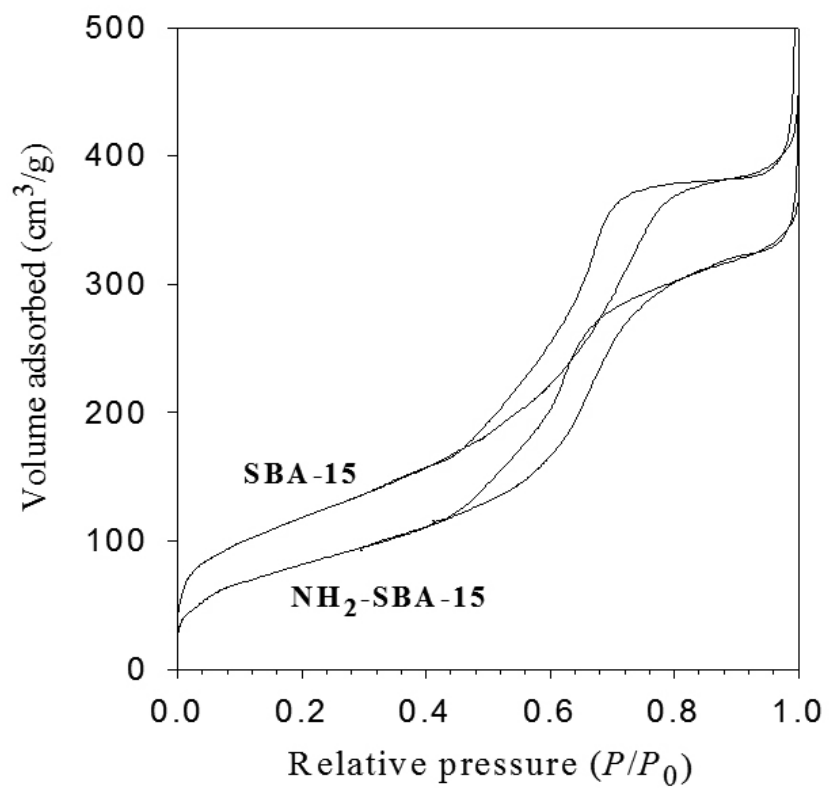

Fig. 2. Nitrogen adsorption-desorption isotherms of SBA-15 and $\mathrm{NH}_{2}-$ SBA-15.

\section{CONCLUSIONS}

In summary, we have reported an easy, efficient and green protocol for the syntheses of spiroacenaphthylene derivatives in ethanol, at room temperature. The simplicity, low reaction time and high yields of products in a green organic solvent are resulted from the efficiency of amino-functionalized silica (SBA-Pr- $\mathrm{NH}_{2}$ ) as a heterogeneous nano catalyst. Reusability of the catalyst and non-chromatographic purification of products, i.e. simple recrystallization is the property of this process.

\section{ACKNOWLEDGEMENTS}

We gratefully acknowledge the financial support from the Research Council of Alzahra University and the University of Tehran.

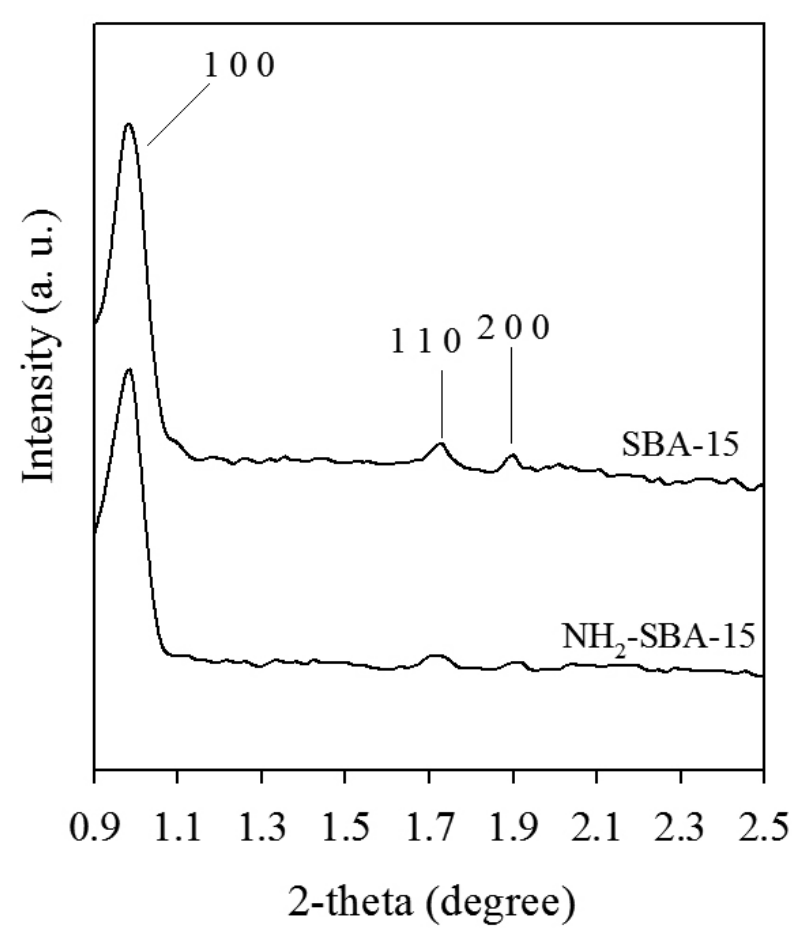

Fig. 3. Low-angle XRD patterns of SBA-15 and $\mathrm{NH}_{2}-\mathrm{SBA}-15$.

\section{REFERENCES}

1. K.A. Parker, A. Dermatakis, J. Org. Chem. 62, 4164, (1997)

2. M.J. Kukla, H.J. Breslin, C.J. Diamond, P.A.J. Janssen, J. Med. Chem. 34, 3187, (1991)

3. R. Pradhan, M. Patra, A.K. Behera, B.K. Mishra, R.K. Behera, Tetrahedron $62,779,(2006)$

4. J. Poupaert, P. Carato, E. Colacillo, Curr. Med. Chem. 12, 877, (2005)

5. B. Le Bourdonnec, R.T. Windh, L.K. Leister, Q.J. Zhou, C.W. Ajello, M. Gu, G.H. Chu, P.A. Tuthill, W.M. Barker, M. Koblish, D.D. Wiant, T.M. Graczyk, S. Belanger, J.A. Cassel, M.S. Feschenko, B.L. Brogdon, S.A. Smith, M.J. Derelanko, S. Kutz, P.J. Little, R.N. DeHaven, D.L.H. DeHaven, R.E. Dolle, J. Med. Chem. 52, 5685, (2009)

6. B. Schaudel, C. Guermeur, C. Sanchez, K. Nakatani, J.A. Delaire, Mater. J. Chem. 7, 61, (1997)

7. J. Skommer, D. Wlodkowic, M. Mättö, M. Eray, HA14-1, J. Leuk. Res. 30, 322, (2006)

8. a) B.M. Trost, Science 254, 1471, (1991); b) L.F. Tietze, Chem. Rev. 96, 115 (1996); c) P.A. Wender, S. Handy, D.L. Wright, Chem. Ind. 1997, 767, (1997); d) S.L. Schreiber, Science 287, 1964, (2000)

9. a) J. Zhu, H. Bienayme, Multicomponent reactions, Wiley-VCH, Weinheim, Germany 2005; b) J. Zhu, Eur. J. Org. Chem. 2003, 1133, (2003); c) M. Murakami, Angew. Chem. Int. Ed. 42, 718, (2003); d) C. Simon, T. Constantieux, J. Rodriguez, Eur. J. Org. Chem. 2004, 4957, (2004); e) P. Tempest, Curr. Opin. Drug Discovery Dev. 8, 776, (2005); f) L. Weber, Curr. Med. Chem. 9, 2085, (2002).

10. a) G. Mohammadi Ziarani, A. Badiei, A. Abbasi, Z. Farahani, Chin. J. Chem. 27, 1537, (2009); b) G. Mohammadi Ziarani, A. Badiei, S. Mousa- 
vi, N. Lashgari, A. Shahbazi, Chin. J. Cat. 33, 1832, (2012); c) G. Mohammadi Ziarani, N. Hosseini Mohtasham, N. Lashgari, A. Badiei, M. Amanlou, R. Bazl, JNS 2, 487, (2013).

11. M. Saeedi, M.M. Heravi, Y.S. Beheshtiha, H.A. Oskooie, Tetrahedron 66, 5345, (2010)

12. M.N. Elinson, A.I. Ilovaisky, V.M. Merkulova, P.A. Belyakov, F. Barba, B. Batanero, Tetrahedron 68, 5833, (2012)

13. M. Dabiri, M. Bahramnejad, M. Baghbanzadeh, Tetrahedron 65, 9443 (2009)

14. A. Badiei, H. Goldooz, G. Mohammadi Ziarani, Appl. Surf. Sci. 257, 4912, (2011)
15. A. Shahbazi, H. Younesi, A. Badiei, Chem. Eng. J. 168, 505, (2011)

16. M.A.S. Chong, X.S. Zhao, J. Phys. Chem. B 107, 12650, (2003)

17. A.P. Thottumkara, M.S. Bowsher, T.K. Vinod, Org. Lett. 7, 2933, (2005)

18. a) R.A. Van Santen, M. Neurock, Molecular heterogeneous catalysis: A conceptual and computational approach, Weinheim, Wiley-VCH, Germany 2006; b) K.A. Rocha, I.V. Kozhevnikov, E.V. Gusevskaya, Appl. Catal. A 294, 106, (2005); c) Z. Li, X. Ma, J. Liu, X. Feng, G. Tian, A. Zhu, J. Mol. Catal. A: Chem. 272, 132, (2007); d) I.M. Vilella, I. Borba'th, J.L. Margitfalvi, K. La'za'r, S.R. de Miguel, O.A. Scelza, Appl. Catal. A 326, 37, (2007); e) H.R. Shaterian, H. Yarahmadi, M. Ghashang, Turk. J. Chem. 33, 449, (2009) 